\title{
Perinatal outcome in abnormal placental villus proliferation and mesenchymal dysplasia
}

\author{
Ashwini V. Vhatkar, Pooja K. Bandekar*, Anupama Kanwar, Minnie Bodhanwala
}

\begin{abstract}
Department of Obstetrics and Gynecology Seth G.S. Medical College and Nowrosjee Wadia Maternity Hospital Parel
\end{abstract} Mumbai, Maharashtra, India

Received: 09 November 2020

Accepted: 29 December 2020

\section{*Correspondence:}

Dr. Pooja K. Bandekar,

E-mail: pujuobgy@gmail.com

Copyright: (c) the author(s), publisher and licensee Medip Academy. This is an open-access article distributed under the terms of the Creative Commons Attribution Non-Commercial License, which permits unrestricted non-commercial use, distribution, and reproduction in any medium, provided the original work is properly cited.

\begin{abstract}
Placental mesenchymal dysplasia (PMD) is a rare vascular anomaly which is characterized by mesenchymal stem villous hyperplasia and placentomegaly. Since the modality of treatment changes it is necessary to distinguish PMD from molar pregnancy, placenta mosaicism, chorioangioma, twin pregnancy with co-existent molar pregnancy. On reviewing cases of abnormal placental villus proliferation having features of placental mesenchymal hyperplasia placentomegaly and cystic appearance of placenta in database of our hospital from 2015-2019, we reported 4 cases of abnormal placental villous proliferation. And performed systematic review of existing literature. Provisional diagnosis of PMD was made as USG and placental morphology showed 30-60\% of the placenta with cystic vesicles, placentomegaly with a normal growing fetus. PMD an uncommon vascular anomaly which resembles molar pregnancy but prognosis is different. The fetus was normal in majority of the cases. This clinical entity should be kept in mind to avoid unnecessary termination of pregnancy.
\end{abstract}

Keywords: Partial hydatidiform mole, Placental mesenchymal dysplasia, Placentomegaly

\section{INTRODUCTION}

Placental mesenchymal dysplasia, recently known as placental mesenchymal hyperplasia is an uncommon placental vascular anomaly characterized by placental stem villous hyperplasia and placentomegaly. The incidence of PMD is reported to be $0.02 \%$ so far more than 100 cases have been reported in literature. ${ }^{1}$ The true incidence of PMD is unknown because it has been previously reported under a variety of names such as placentomegaly with massive hydrops of placental stem villi and pseudo partial moles. In addition, PMD remains unfamiliar to many pathologists and for these reasons it is believed that PMD is both underdiagnosed and underreported distinguishing PMD from molar pregnancy, is important to prevent the unnecessary termination of pregnancy. ${ }^{1}$ The differential diagnosis of PMD includes partial molar pregnancy, complete mole with coexisting normal fetus, chorioangioma, subchorionic hematoma, and spontaneous abortion with hydropic changes. Unlike molar pregnancies, PMD usually involves a normal fetus. However, PMD has a high incidence of fetal growth restriction (FGR) and intrauterine fetal death (IUFD), and it has been associated with Beckwith-Wiedemann syndrome (macrosomia, visceromegaly, macroglossia, and omphalocele). ${ }^{3}$

In reviewing PMD cases diagnosed at our institution and performing a systematic review of the existing literature, our objectives were to identify sonographic findings indicative of PMD. We also sought to investigate the outcomes of pregnancies associated with PMD. By collecting and systematically reviewing the data we are able to provide clinicians with more detailed information for counseling patients on the implications and prognosis of PMD. ${ }^{2}$ 


\section{CASE SERIES}

We reviewed cases of abnormal placental villus proliferation having features of placental mesenchymal hyperplasia placentomegaly and cystic appearance of placenta in database of our hospital from 2015-2019, we reported 4 cases of abnormal placental villous proliferation and compared it with data available in literature favorable perinatal outcome in three cases and one case had abortion at 25.2 weeks.

\section{Case 1}

A 20-year-old patient gravida 1 , abortion 1 with 26.5 week of gestation referred to hospital with an ultrasound which showed structurally normal fetus with $6^{\text {th }}$ centile growth and a co-existent vesicular mole. All hematological and biochemical parameters were within normal limits.

An ultrasonography was further repeated to confirm the diagnosis which showed multiple vesicles within placenta and about $60 \%$ of the placenta showed such vesicles and no abnormal blood supply in the vesicles, with a normal growing fetus with no malformations. A provisional diagnosis of placental mesenchymal dysplasia with normal fetus made. Serum beta hCG was within normal limit.

She was monitored with fetal doppler twice weekly non stress test was done and hematological and biochemical investigations were also repeated. She carried her pregnancy till 36 weeks without any complications, at 36.4 weeks she was admitted as her ultrasound showed IUGR with normal doppler flows for further management. Patient went into spontaneous labour at 37.4 and delivered a female fetus weighing $2.2 \mathrm{~kg}$ vaginally, placenta and membranes expelled out completely and spontaneously. Placenta was weighing $780 \mathrm{gm}$.

Fetal karyotyping was done with showed 46XX, no mosaic and aneuploidy. Histopathology of the placenta was showing multiple trophoblastic cystic lesions with hydropic stem villi interspaced within normal villi and few congest blood vessels.

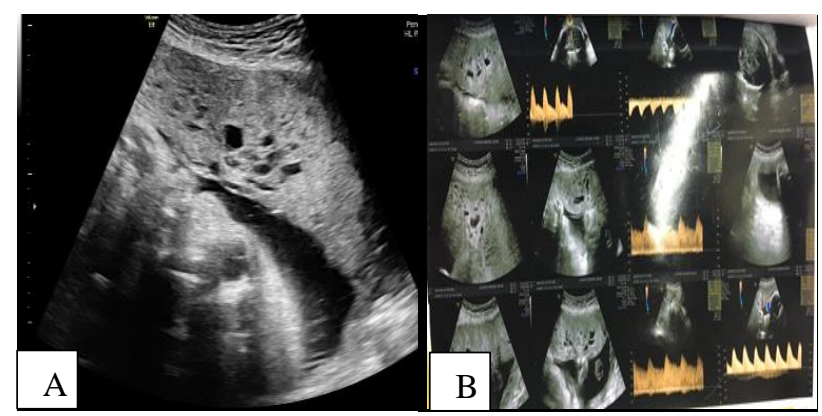

Figure 1: (A and B) USG of multiple vesicles with normal blood flow.

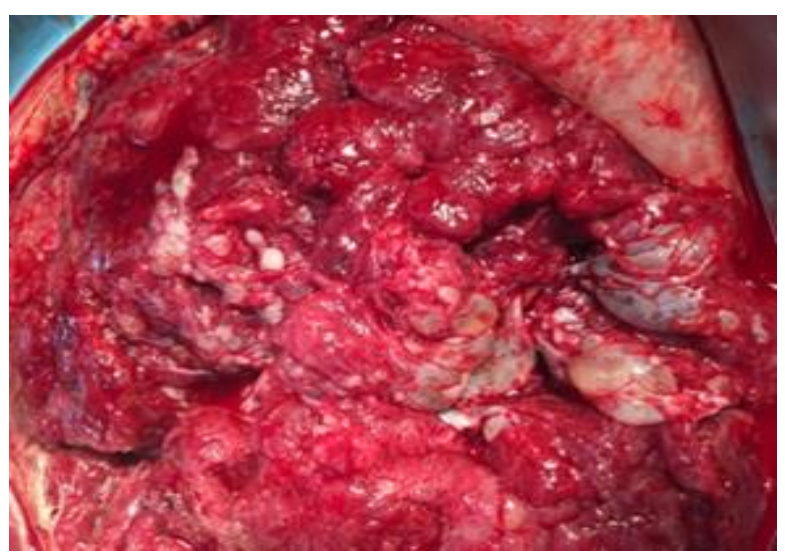

Figure 2: Placenta with grape like vesicles.

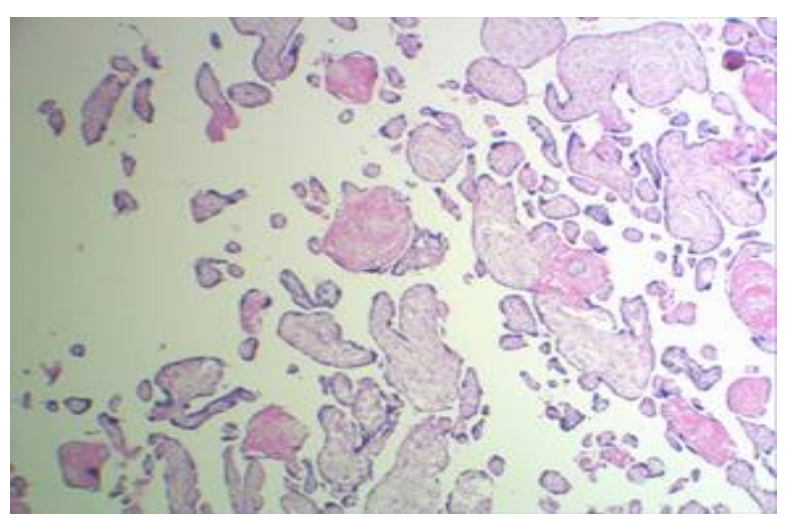

Figure 3: Histopathology s/o hydropic villi, interspaced with normal villi.

\section{Case 2}

A 25-year-old primigravida with 32 weeks of gestation with a history of controlled gestational hypertension on medication came to the hospital with complaints of decreased fetal movement. It was a spontaneous pregnancy with no other co morbidities reported. All the hematological and biochemical examination were normal. The first USG was done at 12 weeks of gestation which showed single uterine artery with structurally normal fetes, NT and NB scan were normal. The second scan was done at 19 weeks of gestation which showed no malformation, with multiple cysts in placenta with low impedance flow. Third USG and doppler done at 28 weeks of gestation showed IUGR with normal AFI with multi cystic appearances. The doppler studies showed high PI in umbilical artery and absent end diastolic flow. Steroid cover was given. Doppler studies were repeated again after 2 weekly at 32 weeks showed absent end diastolic flow. The decision of termination of pregnancy was taken and elective LSCS was done at 32 weeks. Female child weighing $1280 \mathrm{gm}$ was delivered and was shifted to NICU for further care and management.

On examination placenta showed multi cystic appearances and was sent to histopathology examination. 
Fetal karyotyping was done which showed normal fetal karyotype 46XX. Female child was transferred to the mother after one month of NICU stay.

HPE of placenta showed placental dysplasia with multiple hydropic villi.

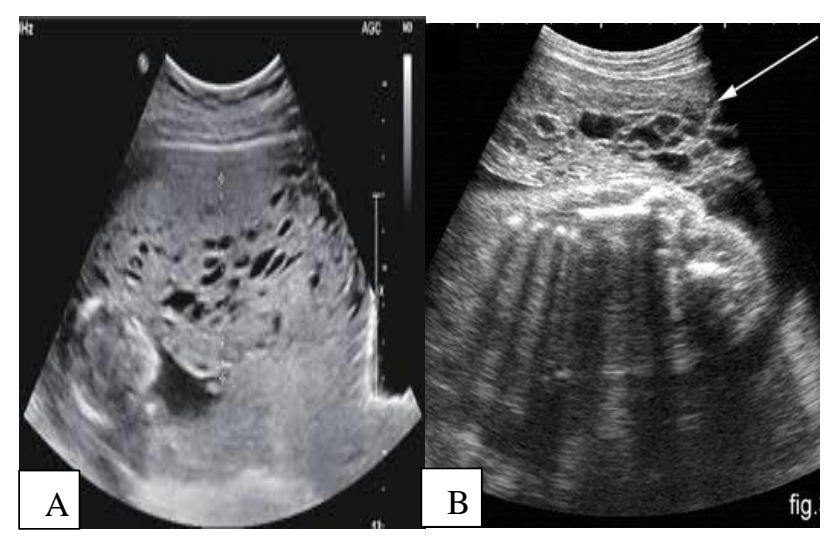

Figure 4: (A and B) USG of multiple cystic appearance of placenta.

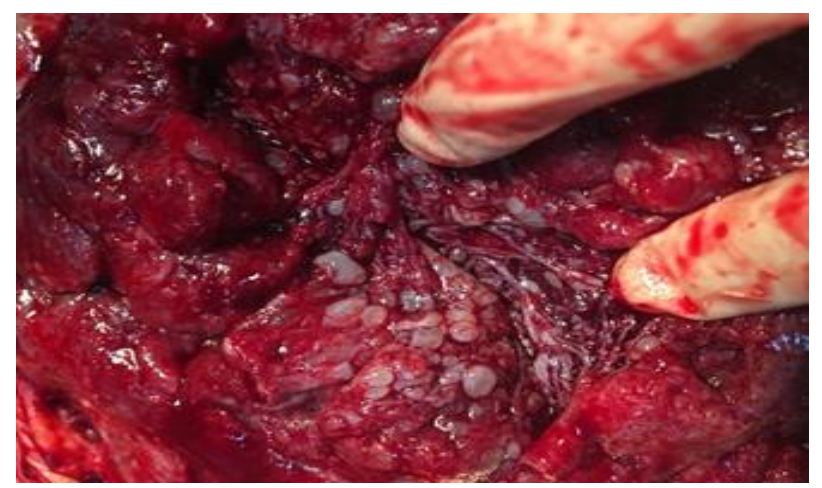

Figure 5: Hydropic villi.

\section{Case 3}

A 28-year-old female G3P1L0NND1A1 referred to tertiary hospital for IUGR with doppler changes with didelphic uterus with absent right kidney of the mother.

She was antenatal registered at private hospital at 12 weeks and routine USG was done which showed normal NT/NB scan. Dual markers were done it showed low risk for Downs syndrome. Anomaly scan done at 19 weeks 3 days showed normal fetus with thickened placenta with large cyst of $5 \times 5 \mathrm{~cm}$. Patient was offered amniocentesis but she refused. Rest antenatal follow up was done regularly and routine biochemistry was within normal limit. Repeat USG done at 26 weeks showed placentomegaly (placental thickness $>5 \mathrm{~cm}$ ) with large placental cyst of $73 \mathrm{x} \mathrm{cm}$ few small cyst, with asymmetrical intrauterine growth restriction with 5 weeks' lag, with compensatory changes in MCA, she was then hospitalized for further management. She was monitored with doppler weekly, liquor, interval growth at
28 weeks scan showed reversal of flows in umbilical arteries AFI 4-5 cm required emergency LSCS, baby weighing $960 \mathrm{gm}$ delivered and shifted to NICU. Placental showed placentomegaly and weighted $900 \mathrm{gm}$ with large cyst of $6 \times 4$ along with some small cyst on gross examination. Fetal karyotype was 46XX and histopathology of placenta showed hydropic placental villi interspaced with normal villi without trophoblastic proliferation

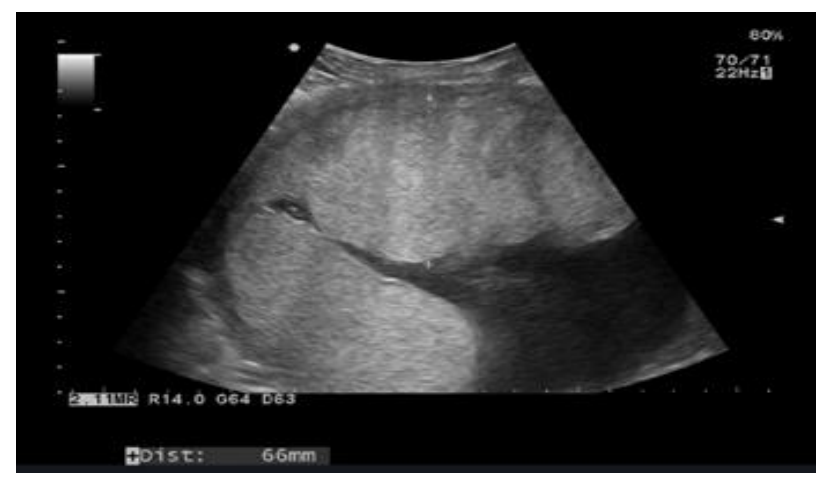

Figure 6: USG of large hydropic cyst of placenta.

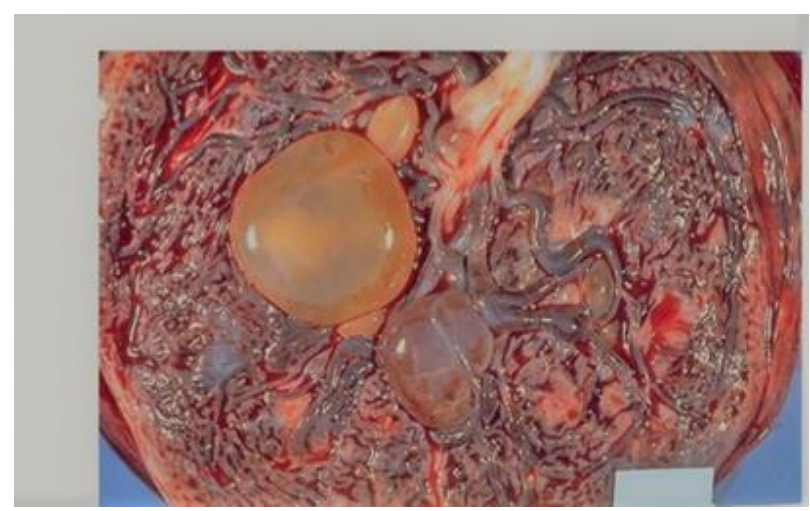

Figure 7: Gross appearance of placenta with single large cyst with multiple small cyst.

\section{Case 4}

A 35-year-old woman, gravida 3 (term births 0 , premature births 0 , abortus 2 , living children 0 presented at 19 weeks 4 days for a DCDA twins with suspected molar pregnancy. It was a twin gestation following invitro fertilization with donor eggs. The quantitative beta human chorionic gonadotropin $(\beta \mathrm{hCG})$ level was elevated at $239000 \mathrm{mIU} / \mathrm{mL}$. The placenta was enlarged and hydropic, and death of single twin at 19 weeks 5 days. The patient underwent chorionic villus sampling and the karyotype was 46, XX. Genotyping ruled out a molar pregnancy. A follow up ultrasound at 24 weeks' gestation again revealed an enlarged placenta with multiple cystic areas. The patient was counseled on the possible diagnosis of a molar pregnancy co-existent with a normal fetus. She continued to opt for expectant management. At 26 weeks 4 days, she presented to the complaining of vaginal spotting with her cervix dilated $2.5 \mathrm{~cm}$. The 
patient was counseled on the poor prognosis for the pregnancy, including the risks of infection, and still desired expectant management. She returned at 28 weeks with preterm premature rupture of membranes (PPROM) and was dilated 3-4 $\mathrm{cm}$. She delivered $650 \mathrm{gm}$ of live baby shifted to NICU. There were no fetal anatomic abnormalities. The B-hCG level was $5490 \mathrm{mIU} / \mathrm{mL}$ and it normalized after 6 weeks. The placenta was enlarged at $635 \mathrm{gm}$ with dilated chorionic plate vessels. On histopathology the stem villi were edematous with prominent thick-walled blood vessels and the terminal villi were focally hydropic. Trophoblastic proliferation and stromal inclusions were not observed. Final diagnosis of twin gestation with PMD was made
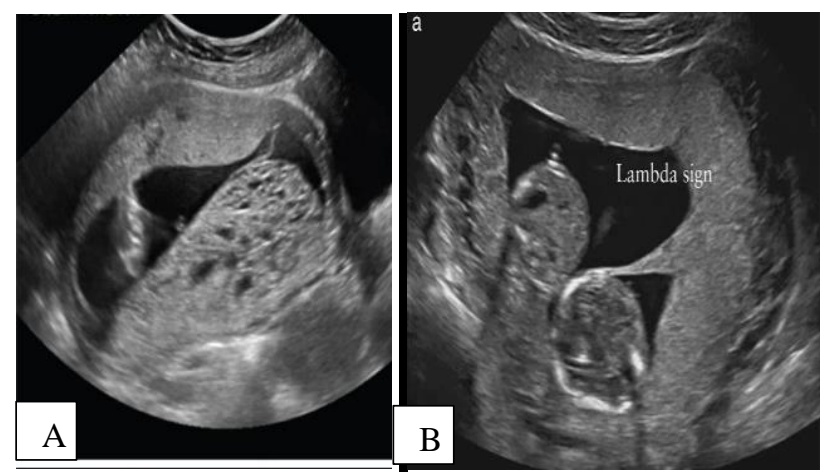

Figure 8: (A and B) Twin gestation with multiple placental cysts.

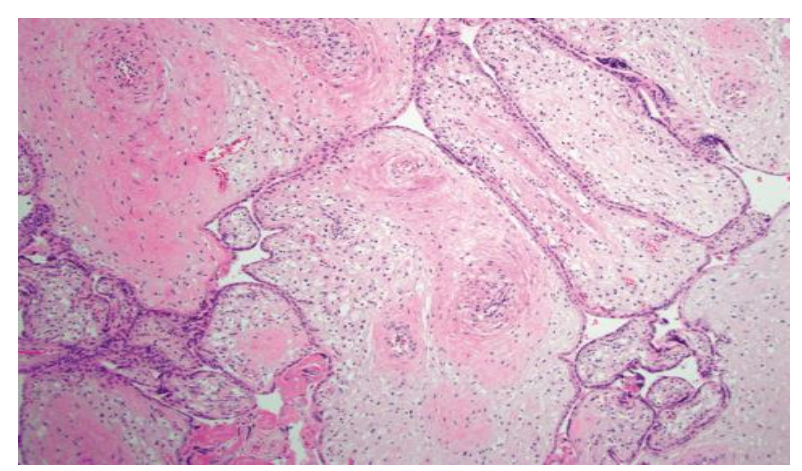

Figure 9: HPR the stem villi were edematous with prominent thick-walled blood vessels and the terminal hydropic villi.

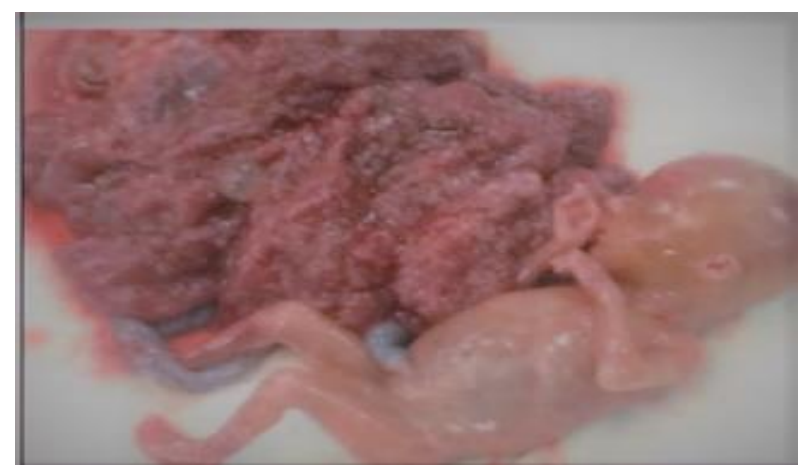

Figure 10: Fetus with hydropic placenta.

\section{DISCUSSION}

PMD is a rare and fairly new diagnosis first termed in 1991. ${ }^{1}$ The term placental mesenchymal dysplasia was chosen in 1991 by Moscoso et al to characterize a placental lesion previously reported in the literature as placentomegaly with massive hydrops of placental stem villi and pseudo partial mole. ${ }^{1}$ Placental mesenchymal dysplasia is an unusual abnormality of the stem villi of the placenta that may be mistaken for a hydatidiform mole, and in particular, partial mole, owing to the mixture of cysts and normal-appearing parenchyma. Placental mesenchymal dysplasia shows stem villous cystic dilation and vesicle formation, placentomegaly, and vascular abnormalities. $^{2}$

Pathologically, in PMD, placentas are usually large in size and show edema of stem villi with intact terminal villi and many kinds of vascular anomalies. Absence of trophoblastic proliferation in PMD placentas is the main histological difference from partial moles.

It is postulated that PMD occurs when 1 ovum is fertilized by 2 spermatozoa or involves a single ovum and spermatozoa with a maternal nondisjunction error during the first meiotic division. The former produces a mix of diploid and paternal isodisomic cell lines and the latter, androgenic chimerism.

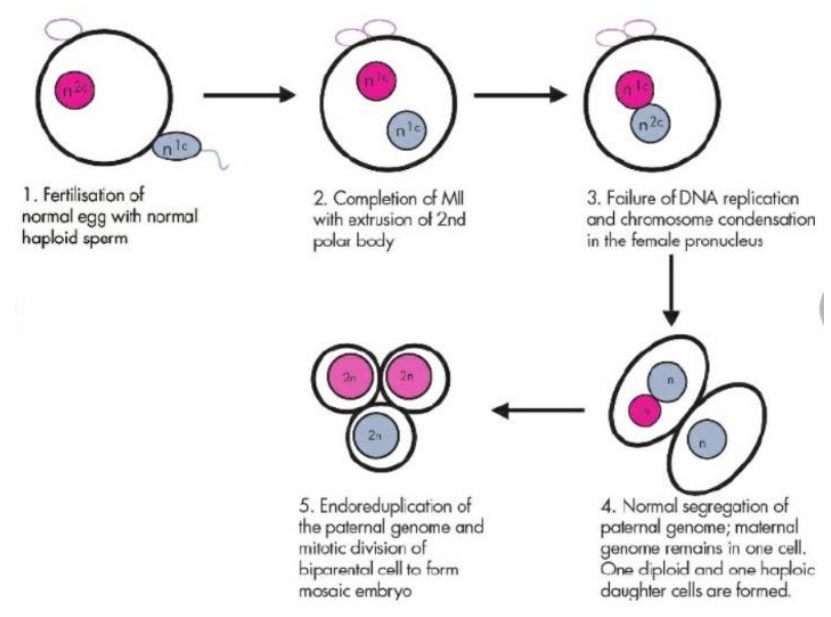

Figure 11: Diagramatic representation of androgenic/biparental mosaicism.

More recently, androgenic/biparental mosaicism has been suggested by Kaiser-Roger et al as the underlying cause of PMD, supported by the finding of 2 separate cell lines in PMD placental tissue. In this condition, the androgenic cell line is thought to arise from endoreduplication of the haploid paternal genome, whereas the biparental cell line arises from the combination of the haploid maternal and the paternal genomes. However, the presence of the same paternal haploid complement in both cell lines suggests paternal uniparental isodisomy and involvement of only a 
single egg and sperm nucleus. The abnormal androgenetic cells are confined to chorionic mesoderm, membranes, and vessels, whereas the trophoblastic cells are normal with no evidence of androgenetic cells this explains the absence of trophoblast overgrowth in PMD in contrast to complete moles in which androgenetic cells are identified in the trophoblastic cell layer. ${ }^{4}$ Studies have shown a female predominance in cases of PMD and it is speculated that there is a relationship to the $X$ chromosome, although an exact underlying mechanism is not yet fully known. Female predominance can also be explained by androgenetic/biparental mosaicism. Because the androgenetic cell line has arisen from duplication of the haploid paternal genome, it is likely this would give rise to the 46, XX cell line because 46, YY cell lines are incompatible with life. However, because cases of PMD with male foetuses have been reported, it seems that the aetiology of PMD is heterogenous. ${ }^{4}$

Ultrasonography, RI, amniocentesis is used to diagnose PMD. On USG the placenta is thickened with multiple cystic or hypoechoic areas. Doppler findings are variable. There are many documented cases of no vascularity within the lesion and further development of vascularity within. These changes could be due to progressive dilatation of chorionic arteries and veins that become aneurysmal. Furthermore, the diagnosis can be confirmed by MRI and histopathology.

It is important to distinguish PMD from molar pregnancy because it may avoid unnecessary termination of pregnancy especially if prenatal ultrasonographic examination shows feature suggestive of molar pregnancy in the presence of a normal-appearing foetus. The main differential diagnoses of PMD, both clinically and pathologically, are partial hydatidiform moles, a twin gestation with complete mole, spontaneous abortion with hydropic changes, and placental mosaicism. Unlike partial moles, the placenta in PMD is almost always diploid (except in rare instances), and histologically the villi do not show proliferation of trophoblasts or stromal trophoblastic inclusions. The triploid foetus associated with a partial mole shows growth restriction with a variety of external and internal defects. In twin gestations with complete moles, the abnormal fetal vessels in the stem villi characteristic of PMD are absent even though the foetus may have a diploid karyotype. The vesicles in hydropic spontaneous abortion, if present, are usually small and are not diffuse. Second, the histology of spontaneous abortions shows degenerative changes without the classic histopathology features of PMD.

Placental mesenchymal dysplasia is associated with intrauterine growth restriction and intrauterine fetal demise. Placental mesenchymal dysplasia is also frequently associated with Beckwith-Wiedemann syndrome, transient neonatal diabetes mellitus, paternal uniparental disomy 6 , and trisomy 13 , and Klinefelter syndrome. Placental mesenchymal dysplasia has a female predominance, and the additional $\mathrm{X}$ chromosome in
Klinefelter syndrome is thought to allow for male survival. $^{4-8}$

Maternal complications associated with PMD are comparatively rare. Gestational proteinuria hypertension has been reported, but it is believed that hypertension in these cases is probably a coincidental finding rather than any specific association with PMD. Similarly, polyhydramnios may occur as a result of swallowingrelated problems because of macroglossia in a BWS fetus. ${ }^{6}$ However, it should be noted that $15 \%$ of BWS cases are familial, and theoretically there is a small increased chance of having recurrence of PMD in such families.

\section{CONCLUSION}

PMD is a relatively rare entity that needs to be distinguished from molar pregnancy to clinically prevent unnecessary termination of the pregnancy. If PMD is suspected after antenatal ultrasonography and genetic testing, it is imperative that affected patients be followed up as patients with high-risk pregnancies owing to the association with growth restriction, stillbirth, and other chromosomal abnormalities. The pathologic features in the placenta need to be recognized and distinguished from other placental abnormalities, including molar pregnancy, to aid in clinical decision making with the patient as to future pregnancies and pregnancy outcomes.

\section{ACKNOWLEDGMENTS}

The authors would like to thank to consultants/residents at the departments of obstetrics and gynecology and pathology and radiology also the medical record dept. for their roles in making this research possible.

Funding: No funding sources

Conflict of interest: None declared

Ethical approval: Not required

\section{REFERENCES}

1. Parveen Z, Tongson-Ignacio JE, Fraser CR, Killeen JL, Thompson KS. Placental Mesenchymal Dysplasia. Arch Pathol Lab Med. 2007;131(1):1317.

2. Nayeri UA, West AB, Nardini GJA, Copel AK, Sfakianaki AK. Systematic review of sonographic findings of placental mesenchymal dysplasia and subsequent pregnancy outcome. Ultrasound Obstet Gynecol. 2013;41(4):366-74.

3. Pawoo N, Heller DS. Placental Mesenchymal Dysplasia. Arch Pathol Lab Med. 2014;138(9):12479.

4. H'mida D, Gribaa M, Yacoubi T, Chaieb A, Adala L, Elghezal $\mathrm{H}$ et al. Placental mesenchymal dysplasia with Beck-Wiedemann syndrome fetus in the context of biparental and androgenic cell lines. Placenta. 2008;29(5):454-60. 
5. Schuetzle M, Uphoff TS, Hatten BA, Dawson DB. Utility of microsatellite analysis in evaluation of pregnancies with placental mesenchymal dysplasia. Prenat Diagn. 2007;27(13):1238-44.

6. Armes J, McGown I, Williams M, Broomfield A, Gough K, Lehane F, Lourie R. The placenta in Beckwith-Wiedemann syndromegenotype-phenotype associations, excessive extravillous trophoblast and placental mesenchymal dysplasia. Roy Coll Pathol Aust. 2012;44(6):1-9.

7. Schuetzle M, Uphoff TS, Hatten BA, Dawson DB. Utility of microsatellite analysis in evaluation of pregnancies with placental mesenchymal dysplasia. Prenat Diagn. 2007;27(13):1238-44.

8. Aviram R, Kidron D, Silverstein S, Lerer I, Abeliovich D, Tepper $\mathrm{R}$ et al. Placental mesenchymal dysplasias associated with transient neonatal diabetes mellitus and paternal UPD6. Placenta. 2008;29(7):646-9.
9. Mungen E, Dundar O, Muhcu M, Haholu A, Tunca Y. Placental mesenchymal dysplasia associated trisomy 13: sonographic findings. J Clin Ultrasound. 2008;36(7):454-6.

10. Robinson WP, Slee J, Smith N, Watson SK, Lam WL, McFadden DE. Placental mesenchymal dysplasia associated with fetal overgrowth and mosaic deletion of the maternal copy of 11p15.5. Am J Med Genet A. 2007;143A(15):1752-9.

11. Parveen Z, Tongson-Ignacio JE, Fraser CR, Killeen JL, Thompson KS. Placental Mesenchymal Dysplasia. Arch Pathol Lab Med. 2007;131(1):1317.

Cite this article as: Vhatkar AV, Bandekar PK, Kanwar A, Bodhanwala M. Perinatal outcome in abnormal placental villus proliferation and mesenchymal dysplasia. Int J Reprod Contracept Obstet Gynecol 2021;10:727-32. 